Article

\title{
Evaluation of Continuous UVC Treatments and its Combination with UHPH on Spores of Bacillus subtilis in Whole and Skim Milk
}

\author{
María Martinez-Garcia ${ }^{1}$, Jezer N. Sauceda-Gálvez ${ }^{1}$, Idoia Codina-Torrella ${ }^{1}{ }^{1}$, \\ $\mathbf{M}^{a}$ Manuela Hernández-Herrero ${ }^{1} \mathbb{D}$, Ramón Gervilla ${ }^{2} \mathbb{D}$ and Artur $X$. Roig-Sagués ${ }^{1, * \mathbb{D}}$ \\ 1 Centre d'Innovació, Recerca i Transfèrencia en Tecnologia dels Aliments (CIRTTA), XaRTA, TECNIO-CERTA, \\ MALTA-Consolider Team, Departament de Ciència Animal i dels Aliments, Facultat de Veterinària, \\ Universitat Autònoma de Barcelona, 08193 Bellaterra, Spain; maria.martinez.garcia@uab.cat (M.M.-G.); \\ jezernoe.sauceda@e-campus.uab.cat (J.N.S.-G.); idoia.codina@uab.cat (I.C.-T.); \\ manuela.hernandez@uab.cat (M.M.H.-H.) \\ 2 SPTA-Servei Planta Tecnologia Aliments, Universitat Autònoma de Barcelona, c/ de l’Hospital S/N, \\ 08193 Bellaterra (Barcelona), Spain; ramon.gervilla@uab.cat \\ * Correspondence: arturxavier.roig@uab.cat; Tel.: +34-935811960
}

Received: 14 September 2019; Accepted: 24 October 2019; Published: 2 November 2019

\begin{abstract}
The aim of this study was to evaluate the effectiveness of different UVC treatments, alone or in combination with ultra-high pressure homogenization (UHPH) on Bacillus subtilis spores in milk. Spores of B. subtilis (CECT4002) were inoculated in whole and skim milk to an initial concentration about $6 \log \mathrm{CFU} / \mathrm{mL}$. Milk was subjected to different ultraviolet radiation treatments at $254 \mathrm{~nm}$ (UVC) using a concentric tubular reactor in a dose ranging from 10 to $160 \mathrm{~J} / \mathrm{mL}$. Different number of passes were used to adjust the final dose received by the matrix. In general, increasing the number of passes (defined as number of entries to the tunnel-NET) increased the inactivation of spores of B. subtilis. The best lethality results (above $4 \mathrm{Log}$ CFU/mL) were obtained by applying doses from $100 \mathrm{~J} / \mathrm{mL}$ with several NET. When the same doses were achieved with a single pass lethality in most cases did not exceed $1 \log \mathrm{CFU} / \mathrm{mL}$. Increasing the NET also increased the likelihood for the spores to remain longer in the effective distance from the UVC source, estimated as $0.02 \mathrm{~mm}$ for whole milk and $0.06 \mathrm{~mm}$ for skim milk. Combination of UHPH and UVC did not clearly increase the efficiency of a single UVC treatment, and a lower lethality was even observed in some cases. UHPH treatments increased the turbidity and absorption coefficient $(254 \mathrm{~nm})$ of both whole and skim milk.
\end{abstract}

Keywords: UVC; UHPH; milk; Bacillus subtilis

\section{Introduction}

Short-wave ultraviolet radiation (UVC) is a non-thermal technology proposed as an alternative to heat pasteurization that is being investigated nowadays for the reduction of microorganisms in liquid foods that may lead to spoilage and potential health risks for the consumers [1]. The application of UVC using reactors allows processing liquid foods in a continuous regime which increased the interest on this technology because it is easy to use, has a lower cost and offers a better preservation of the nutritional content and quality aspects of foods [2-5]. UVC is lethal for most of microorganisms through the formation of pyrimidine dimers which blocks DNA duplication leading to cell death [6,7]. Moreover, unlike other non-thermal emerging technologies, UVC is capable of inactivating bacterial spores $[8,9]$.

The microbiocidal effect of UVC has been tested in different foodstuffs, such as milk, demonstrating an effectiveness similar to thermal pasteurization [2,10-22]. However, milk presents the limiting factor 
of its high absorption coefficient at $254 \mathrm{~nm}(\alpha(254))$ which reduces the possibility for UVC radiation to penetrate through the matrix and reach those areas farther from the UVC source with the same intensity, underexposing some of the present microorganisms, and consequently, reducing the effectiveness of the UVC treatment [23-26].

In order to increase the microbiocidal efficiency of UVC when a continuous flow reactor is used, both the UVC radiation dose and the flow pattern (laminar flow or turbulent flow) must be correctly adjusted to reduce the distance from the UVC source and the microorganisms to make them access the area were the UVC radiation is more efficient inside the reactor [4]. Two basic designs of continuous flow UVC reactors are the most frequently described in the literature to overcome these inconveniences. Some are based on increasing the turbulence generated inside the system and consequently the probability that all parts of the matrix could get into close contact with the UVC source. The conditions for a turbulent flow are described mathematically by the Reynolds number (Re), a minimum Re of 2100 should be achieved to ensure a sufficient turbulence to guarantee a more homogeneous distribution of the residence times inside the reactor $[24,27]$. The other proposed strategy is to reduce as much as possible the gap between the UVC source (lamp) and the farthest particle of the matrix, reducing the path length through creating a thin film around the UVC source. However, in this system, the flow of the liquid is laminar, and that represents an inconvenience to treat matrices with high $\alpha(254)$. One option to overcome this inconvenience is to pass the matrix several times throughout the reactor or several connected reactors, forcing a mixing effect between each pass that increases the efficiency.

A different strategy to increase the UVC treatments efficiency would be to combine them with another emerging non-thermal technology, such as ultra-high pressure homogenization (UHPH) seeking for a synergic o additive effect following the "hurdle" principle. UHPH has been proposed as a good alternative to thermal pasteurization as it reduces the load of vegetative cells of pathogen and spoilage microorganisms significantly while sparing most of the organoleptic and physicochemical characteristics of raw milk [28-30]. However, its effect on bacterial spores is much more limited [31,32]. Both strategies have been recently tested on Bacillus subtilis inoculated into phosphate-buffer saline solution (PBS), increasing the efficiency compared with both UVC and UHPH single treatments [33]. A complementary effect between these technologies was also reported, as UVC was able to inactivate microorganisms that were resistant to UHPH and vice versa.

The aim of this study was to evaluate the effectiveness of UVC treatments applied in different ways, alone or in combination with UHPH on Bacillus subtilis inoculated in whole and skim milk, and exploring the potential of these technologies to obtain commercial sterile products. Mathematical models were used to determine the importance of the treatment variables on their efficacy.

\section{Materials and Methods}

\subsection{Preparation of the Spore Suspension of B. Subtilis}

The strain used in this study was Bacillus subtilis CECT4002, supplied by the Spanish Type Culture Collection (CECT, University of Valencia, Valencia, Spain). A modification of the UNE EN ISO 13704:2002 procedure [34] was used to obtain the spores. Briefly, the lyophilized culture was rehydrated in $10 \mathrm{~mL}$ of glucose and tryptone broth (TGB: $2.5 \mathrm{~g}$ of yeast extract (Oxoid, Basingstoke, $\mathrm{UK}$ ), $5 \mathrm{~g}$ of tryptone (Oxoid), $1 \mathrm{~g}$ of glucose (Sigma-Aldrich, St. Louis, USA), in $1 \mathrm{~L}$ of distilled water, $\mathrm{pH}$ adjusted to 7.2), and incubated for $24 \mathrm{~h}$ at $30^{\circ} \mathrm{C}$. Two $\mathrm{mL}$ of this culture was transferred to Roux bottles containing yeast extract agar (MYA: $10 \mathrm{~g}$ of meat extract (Oxoid), $2 \mathrm{~g}$ of yeast extract (Oxoid), $15 \mathrm{~g}$ of agar (Oxoid) and $0.04 \mathrm{~g}$ of $\mathrm{MnSO}_{4} \cdot \mathrm{H}_{2} \mathrm{O}$ (Merck, Darmstadt, Germany) in $1 \mathrm{~L}$ of distilled water), which were incubated at $30^{\circ} \mathrm{C}$ for up to 30 days. The formed spores were collected by adding $20 \mathrm{~mL}$ of sterile distilled water to the Roux bottles and scraping the surface with a Digralsky stick. Spore suspensions were pooled and washed four times in $15 \mathrm{~mL}$ cold sterile water by centrifugation at $10,000 \times \mathrm{g}$ for $20 \mathrm{~min}$ at $4{ }^{\circ} \mathrm{C}$ using a Sigma $4 \mathrm{~K} 15$ centrifuge (Sigma Laborzentrifugen $\mathrm{GmbH}$, Osterode am Harz, Germany). The resulting sediment was then suspended in $30 \mathrm{~mL}$ of sterile distilled 
water and subjected to a heat treatment at $75{ }^{\circ} \mathrm{C}$ for $10 \mathrm{~min}$ to ensure the inactivation of vegetative cells. The resulting spore suspension was stored at $4{ }^{\circ} \mathrm{C}$ until use. One $\mathrm{mL}$ of the spore suspension was used to inoculate $1 \mathrm{~L}$ of milk to guarantee a minimum initial load close to $10^{6} \mathrm{CFU} / \mathrm{mL}$.

\subsection{Types of Milk Used}

Two types of locally purchased UHT cow milk were used to carry out this study: whole milk $(3.5 \%$ Fat $)$ and skim milk ( $<0.2 \%$ Fat). The characteristics of the matrices that may influence the efficacy of the treatments were determined with the following methods.

\subsubsection{Absorption Coefficient at $254 \mathrm{~nm}(\alpha(254))$}

It was determined using a Nanophotometer Pearl model spectrophotometer (IMPLEN GmbH, München, Germany) with $1 \mathrm{~cm}$ quartz cuvettes (Fisher Scientific, Hanover, IL, USA). Sample was diluted 1000 fold with distilled water in order to fit into the reliable reading range of the spectrophotometer.

\subsubsection{Turbidity}

It was measured with a portable EPA $2100 \mathrm{Q}$ turbidimeter (HACH, Hospitalet de Llobregat, Spain). Sample was diluted 1000 fold with distilled water in order to fit into the reliable reading range of the turbidimeter. Results were expressed as Nephelometric Turbidity Units (NTU).

\subsection{Application of UVC Radiation Treatments}

\subsubsection{UVC Reactor Features}

A UVC reactor (UV-Therm, Ypsicon S.L., Barcelona, Spain; European Patent EP 2965766-A1) was used in this survey. The reactor was fed by a Flowmaster FMT300 peristaltic pump (ISMATEC Lab. $\mathrm{GmbH}$, Wertheim-Mondfeld, Germany) through a silicone pipe. It has a capacity of $673 \mathrm{~mL}$ of total volume and consists of two low pressure mercury UVC lamps (UV-Consulting Peschl Spain, Castellón, Spain), with a total electrical power of $55 \mathrm{~W}$ and an irradiance of $41 \mathrm{~mW} / \mathrm{cm}^{2}$. Each of the lamps is protected by a $2 \mathrm{~mm}$ thick quartz tube (UV-Consulting Peschl, Geldo, Spain), leaving a radial space to circulate for the food of $1 \mathrm{~mm}$. The internal section of the UVC reactor consists of different concentric cylinders (Figure 1): between sections A and B air circulates to cool the UVC lamp; between sections B and $C$ the food matrix circulates in a layer of $1 \mathrm{~mm}$; externally (between sections $C$ and $D$ ) water flows to control the temperature of the treatments. In this survey, the temperature was adjusted to $20^{\circ} \mathrm{C}$.

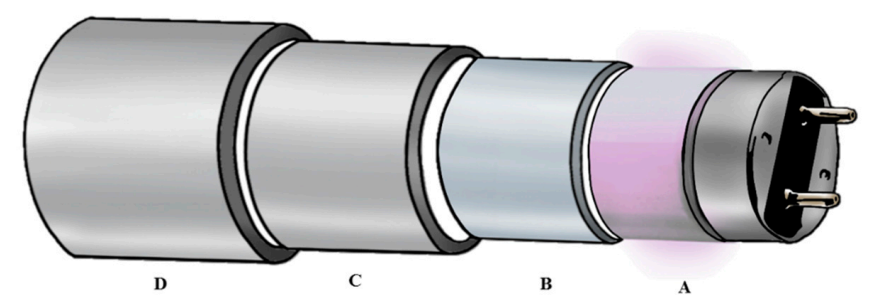

Figure 1. Structure of the UVC reactor used in this survey. A: UVC lamp; B: quartz protection glass; $\mathrm{C}$ and D stainless steel tubes. Section A-B: air circulation; section B-C: food matrix circulation area; section C-D: water cooling system.

\subsubsection{UVC Treatments}

The parameters that defined each UVC treatment were: the UVC energy emitted by the lamp per volume unit (dosimetry); the flow rate at which the sample circulated (expressed as $\mathrm{mL} / \mathrm{s}$ ) and correlated with the revolutions per minute or rpm of the peristaltic pump) that determines the retention time inside the UVC lamp during each pass; and the number of passes through the reactor defined as the number of entries into the reactor or NET. Table 1 shows the combination of these parameters that 
defined each treatment. The different combinations were divided into three groups depending on the flow rate used (T1, T2 and T3). In each group, the final doses achieved ranged from 20 to $160 \mathrm{~J} / \mathrm{mL}$.

Table 1. Parameters of the UVC Treatments Tested.

\begin{tabular}{|c|c|c|c|c|c|c|}
\hline Treatment & Flow Rate (mL/s) & NET & RPM & Retention Time (s) & UVC Dose $(\mathrm{J} / \mathrm{mL})$ & Reynolds Number \\
\hline \multirow{6}{*}{$\mathrm{T} 1$} & \multirow{6}{*}{$\leq 2.9$} & \multirow{6}{*}{2} & 21 & 24 & 20 & 52 \\
\hline & & & 12 & 48 & 40 & 26 \\
\hline & & & 6 & 96 & 80 & 13 \\
\hline & & & 5 & 120 & 100 & 10 \\
\hline & & & 3 & 144 & 120 & 9 \\
\hline & & & 1.5 & 192 & 160 & 7 \\
\hline \multirow{6}{*}{$\mathrm{T} 2$} & \multirow{6}{*}{41.9} & 30 & & 360 & 20 & \multirow{6}{*}{658} \\
\hline & & 60 & & 720 & 40 & \\
\hline & & 121 & & 1440 & 80 & \\
\hline & & 151 & 300 & 1800 & 100 & \\
\hline & & 181 & & 2160 & 120 & \\
\hline & & 241 & & 2880 & 160 & \\
\hline \multirow{6}{*}{ T3 } & \multirow{6}{*}{64.6} & 47 & & 360 & 20 & \multirow{6}{*}{1015} \\
\hline & & 93 & & 720 & 40 & \\
\hline & & 186 & 500 & 1440 & 80 & \\
\hline & & 233 & 500 & 1800 & 100 & \\
\hline & & 279 & & 2160 & 120 & \\
\hline & & 372 & & 2880 & 160 & \\
\hline
\end{tabular}

NET: number of entries to the tunnel; RPM: revolutions per minute (RPM).

\subsubsection{Dosimetry Using a Potassium Iodide/Iodate Actinometer}

In this study, the UVC energy emitted by the lamp per volume unit at $254 \mathrm{~nm}$ was measured by the chemical iodide/iodate actinometer developed and described by Rahn [35] using a solution of potassium iodide that was passed through the UVC reactor. Its absorbance was then measured at $352 \mathrm{~nm}$ using a Nanophotometer Pearl spectrophotometer (IMPLEN) after diluting ten times the sample with distilled water. The formula proposed by Linden and Mofidi [36] was used to calculate the power of the UVC reactor lamps:

$$
\mathrm{H}_{\mathrm{MP}}=\frac{\left(\Delta \mathrm{OD}_{352}\right)(\mathrm{V})(23,786.4)}{(\mathrm{I})(1+0.02(\mathrm{~T}-20.7)) \mathrm{A}}
$$

where $\mathrm{H}_{\mathrm{MP}}$ is the applied UVC dose of the UVC lamp in $\mathrm{mJ} / \mathrm{cm}^{2} ; \Delta \mathrm{OD}_{352} \Delta \mathrm{OD}_{352}$ is the difference of the absorbance of the irradiated sample and absorbance of the untreated (white) sample measured at $352 \mathrm{~nm}$; V is the volume of the irradiated sample in L; I is the path length of light passing through the solution in $\mathrm{cm}$ (in the reactor used it was $0.1 \mathrm{~cm}$ ); $\mathrm{T}$ is the temperature of the treatment, expressed in ${ }^{\circ} \mathrm{C}$; $\mathrm{A}$ is the area of sample facing the light source $\left(700 \mathrm{~cm}^{2}\right)$ and $23,786.4$ is the constant $\left(\mathrm{mJ} / \mathrm{cm}^{2}\right)$ specific for LMP-UVC lamps.

\subsubsection{Determination of the Type of Flow into the Reactor}

To determine the type of flow at which the matrix was circulating through the reactor the Reynolds number (Re) was determined according to the formula described by Müller et al. [37]:

$$
\operatorname{Re}=\frac{d \cdot v \cdot \rho}{\eta}
$$

where $d$ is the diameter of the tube $(\mathrm{m}), \mathrm{v}$ is the velocity $(\mathrm{m} / \mathrm{s}), \rho$ is the fluid density $\left(\mathrm{kg} / \mathrm{m}^{3}\right)$, and $\eta$ is dynamic viscosity of the fluid (Pa.s). The relative viscosity was obtained using an Ostwald 1293 model 
viscometer (CIVEQ, Mexico City, Mexico) and density with a hydrometer-aerometer densitometer HYDR-100-001 (Labbox, Vilassar de Dalt, Spain).

According to that, the flow is considered laminar when the value of Re is less than 2100 and turbulent when it is above 4000. Table 1 shows the Re values obtained in the treated samples.

\subsubsection{Determination of the Effective Depth of UVC}

In liquid matrices of high opacity or turbidity the UVC photons cannot penetrate deeply into the liquid, for this reason, it is necessary to know the depth at which the action of the $\mathrm{UVC}_{254 \mathrm{~nm}}$ radiation is effective. This can be determined by applying the Lamber-Beer law by the equation:

$$
\mathrm{I}=\mathrm{I}_{0} \cdot \mathrm{e}^{-\mathrm{k} \cdot \mathrm{c} \cdot \mathrm{d}}
$$

where I and $\mathrm{I}_{0}$ correspond to the intensity of the UVC radiation expressed in $\mathrm{mW} / \mathrm{cm}^{2} ; \mathrm{I}$ corresponds to the intensity that the matrix receives at a given point, and $\mathrm{I}_{0}$ corresponds to the intensity emitted by the reactor. The constant $\mathrm{k}$ corresponds to the $\alpha(254)$ of the matrix expressed in $\mathrm{cm}^{-1}$; $\mathrm{c}$ is the concentration of solutes capable of absorbing UVC of the sample expressed in mol/L, and finally, $\mathrm{d}$ is the depth or distance at that must UVC light pass through expressed in $\mathrm{cm}$.

\subsection{UHPH Treatments}

For these experiments, an ultra-high pressure homogenizer Stansted FPG12500 (Stansted Fluid Power Ltd., Essex, United Kingdom), with a flow rate of $15 \mathrm{~L} / \mathrm{h}$, was used. The equipment consisted in two intensifiers driven by a hydraulic pump and a pressure valve consisting of a combination of a needle and a zirconium seat, with a cutting angle of $60 \pm 0.5^{\circ}$ at the needle and $45 \pm 0.5^{\circ}$ in the seat. Two heat exchangers (Garvía, Barcelona, Spain) were placed before and after the UHPH equipment to control the inlet and outlet temperatures.

Whole and skim milk inoculated with spores of B. subtilis were treated at a pressure of $200 \mathrm{MPa}$ in a single stage at an inlet temperature of $60^{\circ} \mathrm{C}$. Then, the samples were subjected to the UVC treatment conditions $\mathrm{T} 1$ and $\mathrm{T} 3$ (Table 1).

\subsection{Microbiological Analysis of the Samples and Calculation of the Lethality Achieved}

Once treated, samples were collected aseptically in a Telstar PCR Mini-V biosafety cabinet (Telstar, Terrassa, Spain), in sterile containers, and kept refrigerated $\left(4^{\circ} \mathrm{C}\right)$ until analysis. Ten-fold dilutions were made from each sample in phosphate buffered saline solution consisting of $0.24 \mathrm{~g}$ of $\mathrm{KH}_{2} \mathrm{PO}_{4}$ in $1 \mathrm{~L}$ of distilled water and $\mathrm{pH}$ adjusted to 7.4 (PBS, Panreac). Aliquots of each dilution were plated in Petri plates with trypticase soy agar medium enriched with $0.6 \%$ yeast extract (TSA-YE, Oxoid). The plates were incubated for $24 \mathrm{~h}$ at $37^{\circ} \mathrm{C}$.

The lethality caused by the UVC and/or UHPH treatments on B. subtilis was estimated with the formula:

$$
\text { Lethality }=\log _{10}\left(\frac{\mathrm{N}_{0}}{\mathrm{~N}+1}\right)
$$

where $\mathrm{N}_{0}$ is the initial amount of spores of $B$. subtilis present in the samples before the treatments and $\mathrm{N}$ is the number of remaining viable spores after the treatments, both expressed as in CFU/mL.

\subsection{Determination of the Inactivation Kinetics and Effect of Treatment Variables}

Different statistical models obtained from the results obtained with the different matrices after the UVC treatments (T1, T2 and T3) were elaborated based on the lethality as a response variable, and different explanatory or independent variables: (1) Log C, corresponding to the quantity of inoculated microorganisms expressed as $\log \mathrm{CFU} / \mathrm{mL}$; (2) UVC, the dose of UVC radiation, expressed in $\mathrm{J} / \mathrm{mL}$; (3) the treatment flow rate, expressed in $\mathrm{mL} / \mathrm{s}$; and (4) the NET, expressed as its absolute value. Five models were elaborated: model 1 presents the effect of the combination of variables of dose and 
flow rate with a linear adjustment; model 2 presents the influence of the NET value; model 3 also presents the influence of NET but from a quadratic approach; model 4 included the variables of UVC dose, flow rate and NET with a linear adjustment, and finally model 5 is a quadratic adjust using the variables dose, flow rate and NET.

\subsection{Determination of the UVC Four Decimal Reduction Value (4Duvc)}

Survival data of B. subtilis spores after the different UVC treatments (T1, T2 and T3) were adjusted to different linear and nonlinear models of survival curves (biphasic, Weibull, Weibull with tail, Double Weibull and biphasic models with shoulder) using the GInaFiT software a freeware add-in for Microsoft ${ }^{\circledR}$ Excel [38]. The suitability of the adjustment was determined by determining the root mean square error (RMSE) value and the coefficient $\left(R^{2}\right)$. The $4 \mathrm{D}_{\mathrm{uvc}}$ value that is the UVC dose necessary to reduce $4 \log \mathrm{CFU} / \mathrm{mL}$ of the initial load of the microorganisms tested was determined from the models that show the best adjustment.

\subsection{Statistical Analysis of the Results}

Three independent trials were performed for each experiment and two different samples, from each trial $(n=6)$. Analysis of variance (ANOVA) and Tukey test was used to compare results between treatments and/or matrices. Differences were considered to be significant at $p<0.05$. This analysis was performed with the R system for statistical computation (R Foundation for Statistical Computing, Vienna, Austria 2014, http://www.R-project.org).

\section{Results}

\subsection{Lethal effect of UVC Treatments on Bacillus Subtilis Spores}

Figure 2 shows the lethality results obtained on spores B. subtilis inoculated in whole milk. When a single pass through the reactor was used (T1), lethality was always below $1 \log \mathrm{CFU} / \mathrm{mL}$, and no significant differences $(p \geq 0.05)$ were observed between UVC doses. When the number of passes increased (T2 and T3), there was a significant increase in the lethality value, obtaining a greater reduction in the T3 treatments than in the T2 although differences were reduced when the dose increased. Lethality also increased significantly with the final UVC dose received until achieving a final dose of $80 \mathrm{~J} / \mathrm{mL}$. From this dose and above, statistical differences depending on both NET and the final UVC dose were not observed.

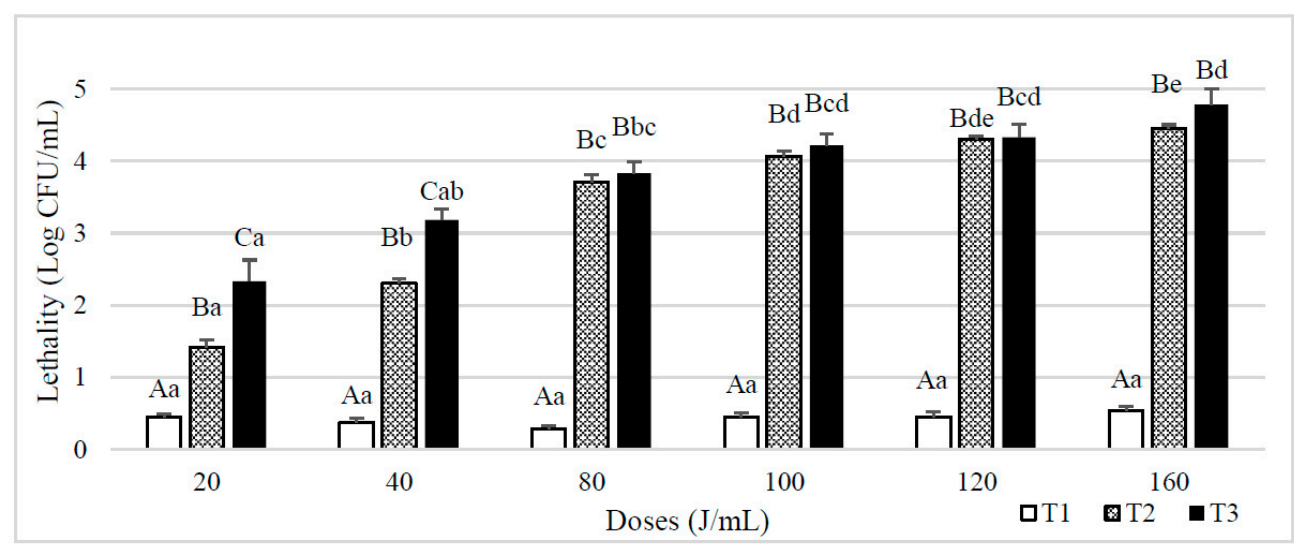

Figure 2. Lethality of B. subtilis spores inoculated in whole milk caused by different UVC treatments consisting of different doses $(\mathrm{J} / \mathrm{mL})$ and number of entries to the reactor (T1, T2 and T3). Results are expressed as $\log \mathrm{CFU} / \mathrm{mL} \pm$ standard deviation. Different lowercase letters in the columns indicate significant differences $(p<0.05)$ between processes with the same flow rate (T1, T2 and T3, see Table 1), but different doses of UVC. Different capital letters indicate significant differences $(p<0.05)$ between processes with different flowrate, but the same dose of UVC. 
When skim milk was inoculated with spores of B. subtilis (Figure 3), similar results were observed. $\mathrm{T} 1$ treatments lethalities were closer to $1 \log \mathrm{CFU} / \mathrm{mL}$ when the UVC dose was of $80 \mathrm{~J} / \mathrm{mL}$ and above, being maximum $(1.2 \log \mathrm{CFU} / \mathrm{mL})$ after a dose of $160 \mathrm{~J} / \mathrm{mL}$. In that case, lethalities also increased when higher NET and UVC doses were applied.

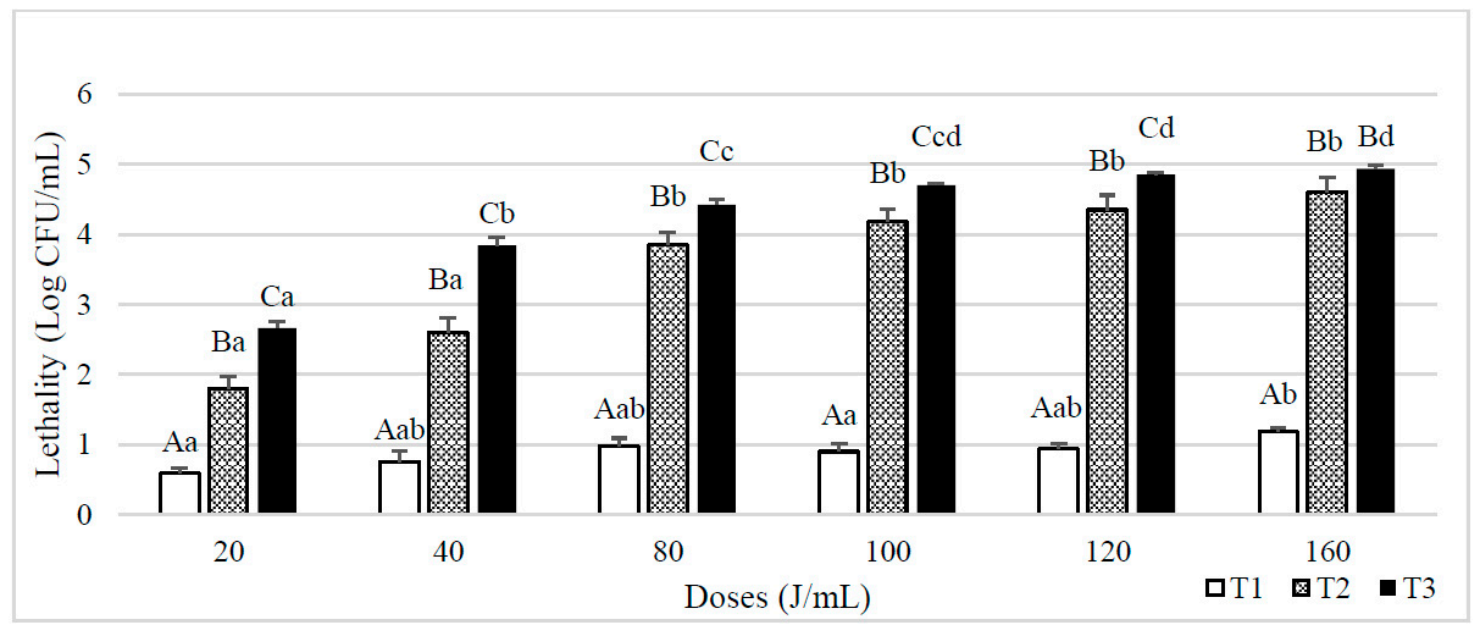

Figure 3. Lethality of $B$. subtilis spores inoculated in skim milk caused by different UVC treatments consisting of different doses $(\mathrm{J} / \mathrm{mL})$ and number of entries to the reactor $(\mathrm{T} 1, \mathrm{~T} 2$ and $\mathrm{T} 3$ Results are expressed as $\log \mathrm{CFU} / \mathrm{mL} \pm$ standard deviation. Different lowercase letters in the columns indicate significant differences $(p<0.05)$ between processes with the same flow rate (T1, T2 and T3, see Table 1$)$, but different doses of UVC. Different capital letters indicate significant differences $(p<0.05)$ between processes with different flowrate, but the same dose of UVC.

Table 2 shows the minimal distance in which the action of UVC radiation is still effective. It was determined at the point where the received dose was $1 \mathrm{~mJ} / \mathrm{cm}^{2}$. Whole milk had the highest $\alpha(254)$, and in consequence, the distance that UVC radiation can penetrate without interference was shorter. Due to this reduced effective distance, increasing the number of passes (determined by the NET), increased the probability for a $B$. subtilis spore to get into this effective zone, increasing the real UVC received dose and consequently the effectiveness of the treatment.

Table 2. Calculation of the effective distance, expressed in $\mathrm{mm}$ where the dose received is close to $1 \mathrm{~mJ} / \mathrm{cm}^{2}$.

\begin{tabular}{ccc}
\hline Matrix & Doses $\left(\mathbf{m J} / \mathbf{c m}^{\mathbf{2}}\right)$ & Effective Distance $(\mathbf{m m})$ \\
\hline \multirow{2}{*}{ Whole milk } & 1.034 & 0.02 \\
& 0.861 & 0.02 \\
\hline \multirow{2}{*}{ Skim milk } & 1.005 & 0.06 \\
& 0.946 & 0.06 \\
\hline
\end{tabular}

\subsection{Lethal Effect of UHPH-UVC Combined Treatments on Bacillus Subtilis Spores}

Figure 4 shows that the lethality obtained when whole milk inoculated with spores of $B$. subtilis was submitted to an UHPH treatment at $200 \mathrm{MPa}$ at an inlet temperature of $60^{\circ} \mathrm{C}$ was below $1 \log \mathrm{CFU} / \mathrm{mL}$. When samples were T1 treated after the UHPH treatment a mean reduction above $1 \log \mathrm{CFU} / \mathrm{mL}$ was achieved, that was statistically greater than those achieved when only a UVC treatment was used $(p<0.05)$. However, when combining the UHPH treatment with the T3 UVC treatments at the mildest doses (20 and $40 \mathrm{~J} / \mathrm{mL}$ ) the lethality obtained was less than in single UVC (T3) treatments, although at higher doses (80-160 J/mL) no significant differences between the combined and simple treatments were observed. 


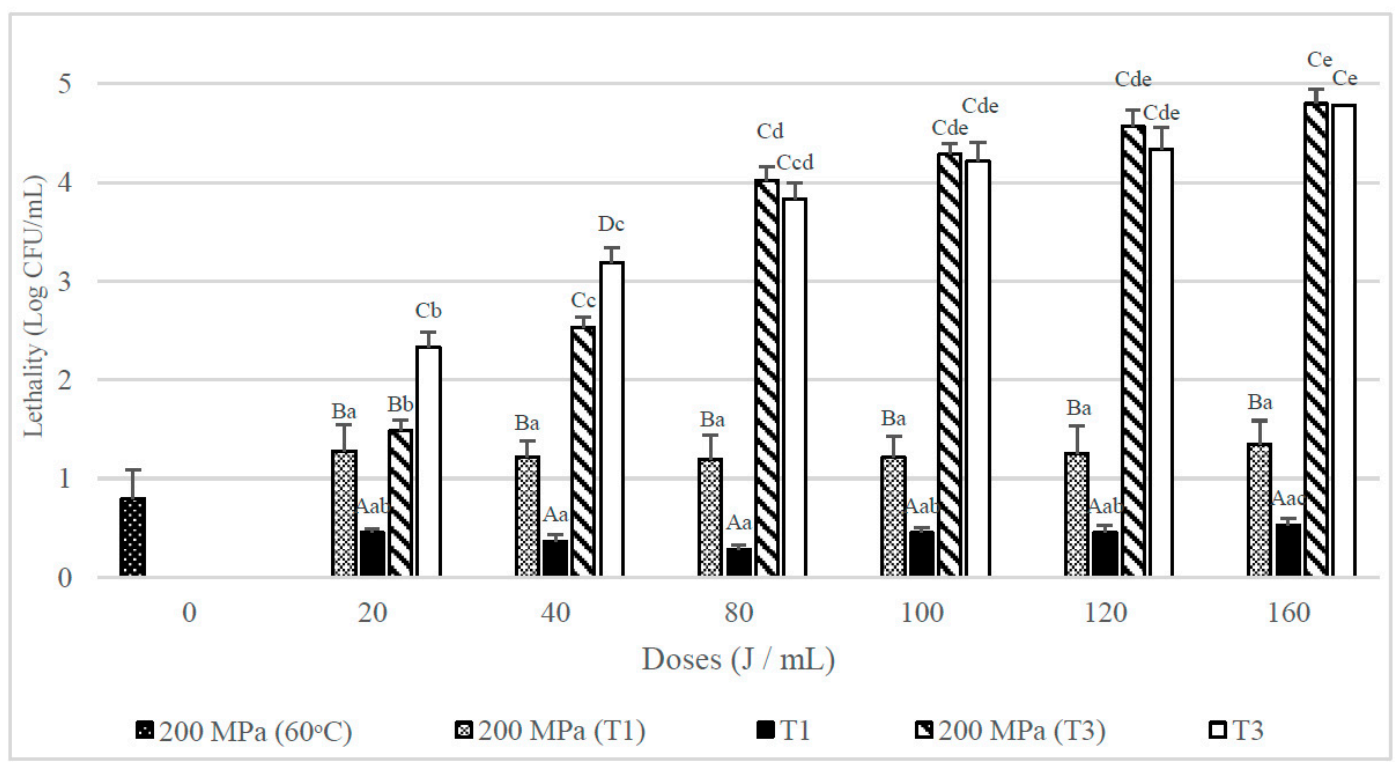

Figure 4. Lethality of B. subtilis spores inoculated in whole milk from UHPH treatments at $200 \mathrm{MPa}$ and UVC treatments at different doses $(\mathrm{J} / \mathrm{mL})$ and their combination with different number of passes (T1 and T3). Results are expressed as $\log \mathrm{CFU} / \mathrm{mL} \pm$ standard deviation. Different lowercase letters in the columns indicate significant differences $(p<0.05)$ between processes with the same flow rate (T1 and T3, see Table 1), but different doses of UVC. Different capital letters indicate significant differences $(p<0.05)$ between processes with different flowrate, but the same UVC dose.

Figure 5 shows that in skim milk, single UHPH treatments applied at 200 MPa hardly affected the viability of the B. subtilis spores inoculated. When it was combined with UVC treatments lethality increased significantly. In contrast, single UHPH treatments, especially when they were combined with T3 UVC treatments, but lethalities were significantly $(p<0.05)$ lower than the obtained when the UVC treatments were used alone.

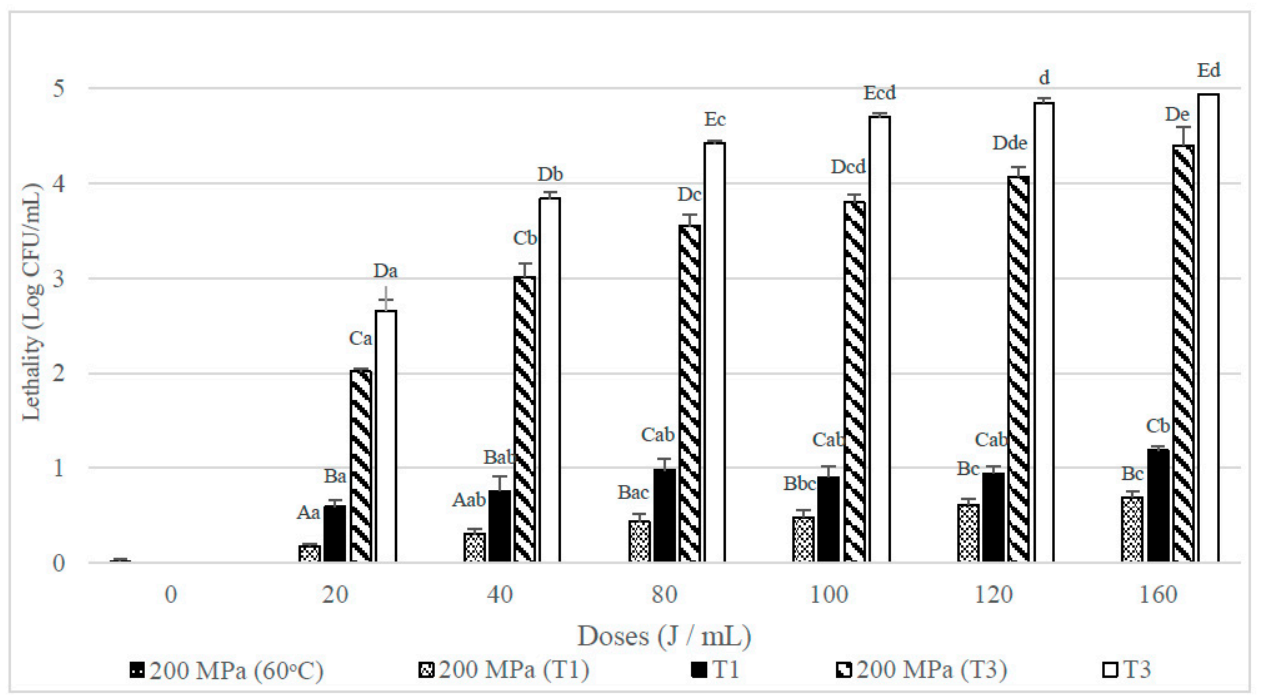

Figure 5. Lethality of B. subtilis spores inoculated in skim milk caused by UHPH treatments at $200 \mathrm{MPa}$ and UVC treatments at different doses $(\mathrm{J} / \mathrm{mL})$ and their combination with different number of passes (T1 and T3). Results are expressed as $\log \mathrm{CFU} / \mathrm{mL} \pm$ standard deviation. Different lowercase letters in the columns indicate significant differences $(p<0.05)$ between processes with the same flow rate (T1 and T3, see Table 1), but different doses of UVC. Different capital letters indicate significant differences $(p<0.05)$ between processes with different flowrate, but the same dose of UVC. 


\subsection{Mathematical Modeling of Treatments}

Because of the scarce, and even negative effect of UHPH treatments, the mathematical modelling was focused on UVC treatments. Table 3 shows the mathematical models obtained according to the lethality of $B$. subtilis spores for both whole and skim milk. The response variable and different explanatory variables were combined in order to find the model where the predicted values were as close as possible to the observed data. In order to carry the choice of the best model, different statistical parameters have been taken into consideration, prioritizing: (1) the adjusted $\mathrm{R}^{2}$ that should be as close as possible to 1 ; (2) the square root of the mean square error (RSME), that should be as low as possible, and finally, (3) the model where the number of variables is the most reduced. According to that, the best model was the Model 3 in both whole and skim milk. This model was a quadratic approach that takes into consideration NET and $\log C$ as variables. The most significant weight in this model was given by the NET value, if the $\log C$ variable is not taken into account. Therefore, the applied dose does not play a determining role in terms of the lethality achieved in the different UVC treatments. This fact confirms that increasing the NET increases the chances for one spore to get into the effective area of the reactor, increasing the time that this spore is exposed to a lethal dose.

Table 3. Mathematical models depending on the lethality UVC treatments on the B. subtilis spores obtained in whole and skim milk.

\begin{tabular}{|c|c|c|c|}
\hline & Models & $R^{2}$ & RMSE \\
\hline \multicolumn{4}{|c|}{ Whole milk } \\
\hline 1 & Lethality $=3.56-0.71 \times \log _{C}+0.015 \times \mathrm{UVC}+0.05 \times \mathrm{R}$ & 0.83 & 0.70 \\
\hline 2 & Lethality $=19.17-3.02 \times \log _{C}+0.012 \times \mathrm{NET}$ & 0.83 & 0.69 \\
\hline 3 & \multirow{3}{*}{$\begin{array}{c}\text { Lethality }=6.557-1.002 \times \log _{\mathrm{C}}+0.029 \times \mathrm{NET}-0.00005 \times \mathrm{NET}^{2} \\
\text { Lethality }=4.86-0.77 \times \log _{\mathrm{C}}+0.0048 \times \mathrm{UVC}+0.029 \times \mathrm{FR}-0.0078 \times \mathrm{NET} \\
\text { Lethality }=2.696-0.39 \times \log _{\mathrm{C}}+0.0012 \times \mathrm{UVC}+0.009 \times \mathrm{FR}+0.027 \times \mathrm{NET} \\
-0.00005 \times \mathrm{NET}^{2}\end{array}$} & 0.94 & 0.40 \\
\hline 4 & & 0.86 & 0.63 \\
\hline 5 & & 0.94 & 0.40 \\
\hline \multicolumn{4}{|c|}{ Skim milk } \\
\hline 1 & Lethality $=-14.74+2.79 \times \log _{C}+0.014 \times$ UVC $+0.017 \times$ FR & 0.91 & 0.52 \\
\hline 2 & Letalidad $=-10.1+2.12 \times \log _{C}+0.0086 \times \mathrm{NET}$ & 0.90 & 0.53 \\
\hline 3 & Lethality $=-4.2+0.97 \times \log _{\mathrm{C}}+0.023 \times \mathrm{NET}-0.00004 \times \mathrm{NET}^{2}$ & 0.95 & 0.36 \\
\hline 4 & \multirow{2}{*}{$\begin{array}{c}\text { Lethality }=-12.53+2.47 \times \log _{\mathrm{C}}+0.0077 \times \mathrm{UVC}+0.0072 \times \mathrm{FR}+0.00472 \times \mathrm{NET} \\
\text { Lethality }=-4.367-0.92 \times \log _{\mathrm{C}}+0.0049 \times \mathrm{UVC}+0.01 \times \mathrm{FR}+0.02 \times \mathrm{NET} \\
-0.00004 \times \mathrm{NET}^{2}\end{array}$} & 0.92 & 0.48 \\
\hline 5 & & 0.96 & 0.34 \\
\hline
\end{tabular}

Log C: quantity of inoculated microorganisms expressed as $\log \mathrm{CFU} / \mathrm{mL}$; UVC, the dose of UVC radiation, expressed in J/mL; FR: treatment flow rate, expressed in $\mathrm{mL} / \mathrm{s}$; NET: number of entries to the tunnel.

\subsection{Kinetics of Inactivation and Estimation of the $D_{u v c}$ Value for the Different UVC Treatments}

The adjustments of the data to the inactivation kinetic models included in the GInaFIT tool are shown in Table 4. As previously described, the root mean square error (RMSE) and the $\mathrm{R}^{2}$ value were used to determine the fitting accuracy.

In the UVC treatments the calculation of the $\mathrm{D}$ value can be of great importance for industries that intend to use this technology to determine the necessary UVC dose to inactivate a specific amount of microorganisms, but in most cases the kinetics of microbial inactivation does not correspond to a linear model and therefore, the calculation of the $\mathrm{D}$ value or the time required to reduce $90 \%$ of the microbial population (a logarithmic unit) is difficult to estimate. In consequence, it is of great importance to apply the appropriate kinetics in each case and to use the models that better adjust to the real data so as not to overestimate the inactivation capacity of the treatment. 
Table 4. Adjustment to kinetic model and estimation of the corresponding $4 \mathrm{D}_{\mathrm{uvc}}$ value (Four decimal reduction value: UVC dose necessary to reduce $4 \log \mathrm{CFU} / \mathrm{mL}$ ) of $B$. subtilis spores in whole and skim milk according to the UVC treatments applied using the GInaFIT tool.

\begin{tabular}{|c|c|c|c|c|c|}
\hline Treatment & Type of Milk & Inactivation Model & RMSE & $R^{2}$ & $4 \mathrm{D}_{\mathrm{uvc}}(\mathrm{J} / \mathrm{mL})$ \\
\hline \multirow{8}{*}{ T1 } & \multirow[t]{4}{*}{ Skim } & Log-Linear Regression & 0.2433 & 0.592 & - \\
\hline & & Log-Linear with tail & 0.2269 & 0.654 & - \\
\hline & & Weibull & 0.2087 & 0.707 & - \\
\hline & & Biphasic & 0.2101 & 0.710 & - \\
\hline & \multirow[t]{4}{*}{ Whole } & Log-Linear Regression & 0.1143 & 0.242 & - \\
\hline & & Log-Linear with tail & 0.2331 & 0.202 & - \\
\hline & & Weibull & 0.2318 & 0.210 & - \\
\hline & & Biphasic & 0.2330 & 0.224 & - \\
\hline \multirow{8}{*}{ T2 } & \multirow[t]{4}{*}{ Skim } & Log-Linear Regression & 0.7050 & 0.769 & - \\
\hline & & Log-Linear with tail & 0.5092 & 0.883 & - \\
\hline & & Weibull with tail & 0.4491 & 0.911 & 89.6 \\
\hline & & Biphasic & 0.4749 & 0.901 & 116.8 \\
\hline & \multirow[t]{4}{*}{ Whole } & Log-Linear Regression & 0.5441 & 0.839 & - \\
\hline & & Log-Linear with tail & 0.2731 & 0.960 & - \\
\hline & & Weibull with tail & 0.2375 & 0.970 & 94.4 \\
\hline & & Biphasic & 0.0646 & 0.966 & 126.4 \\
\hline \multirow{8}{*}{ T3 } & \multirow[t]{4}{*}{ Skim } & Log-Linear Regression & 0.6673 & 0.811 & - \\
\hline & & Log-Linear with tail & 0.3124 & 0.952 & 44.8 \\
\hline & & Weibull with tail & 0.2294 & 0.975 & 43.2 \\
\hline & & Biphasic & 0.2059 & 0.980 & 41.6 \\
\hline & \multirow[t]{4}{*}{ Whole } & Log-Linear Regression & 0.7465 & 0.705 & - \\
\hline & & Log-Linear with tail & 0.3263 & 0.571 & - \\
\hline & & Weibull with tail & 0.4637 & 0.892 & 91.2 \\
\hline & & Biphasic & 0.2157 & 0.464 & 97.6 \\
\hline
\end{tabular}

One of the main impediments to adjust experimental data to a linear model is the appearance of tails or shoulders in the inactivation curves; the presence of shoulders in the curves indicates that, at the beginning of treatment, a decrease in the treated microorganism is not observed despite an increase of the doses. To the contrary, the appearance of tails indicates that although the UVC dose increases, a more resistant population will always be observed. In this survey, when the UVC treatments were adjusted, the appearance of tails was the main problem found there, particularly in treatments $\mathrm{T} 2$ and T3. Whole and skim milk showed the best adjustment to a Weibull model with a tail (Figure 6A,B for T2 and T3 treatments in whole milk and Figure 7A,B for T2 and T3 treatments in skim milk, respectively). This phenomenon indicates that from a dose of $80 \mathrm{~J} / \mathrm{mL}$ there is a slowdown in the speed of inactivation of $B$. subtilis spores, and in consequence, when a higher doses $(100,120$, or $160 \mathrm{~J} / \mathrm{mL})$ were applied spores did not get inactivated at the same inactivation rate than at the lower doses and consequently the inactivation constant were different. The inactivation constant $(\mathrm{k}) \mathrm{can}$ be used to assess the susceptibility of a microorganism to UVC radiation, and it could be a good indicator as long as the kinetic of inactivation of the microorganism is linear and with only one inactivation constant. Due to the appearance of tails or shoulders, in most cases the inactivation kinetics consisted of two inactivation constants. 
A

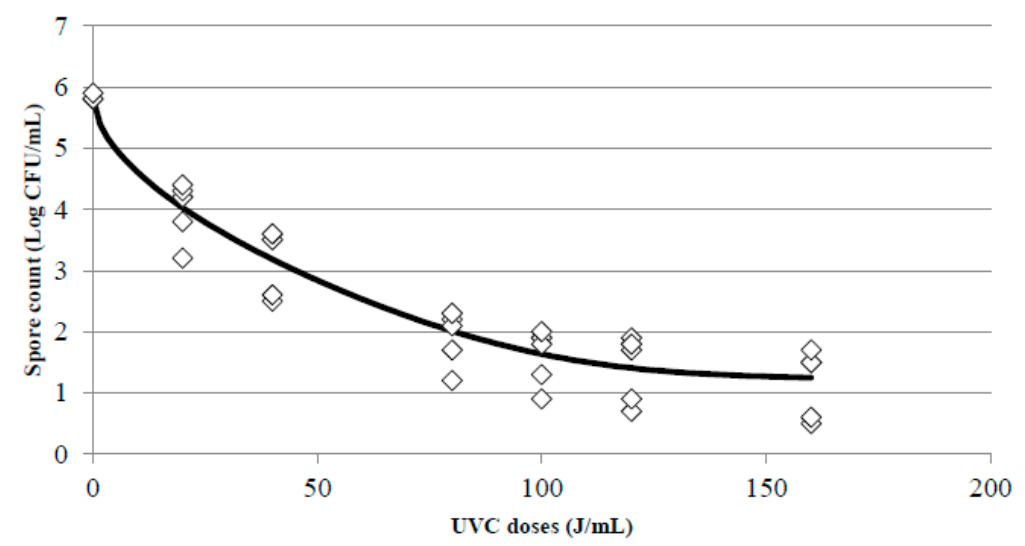

B

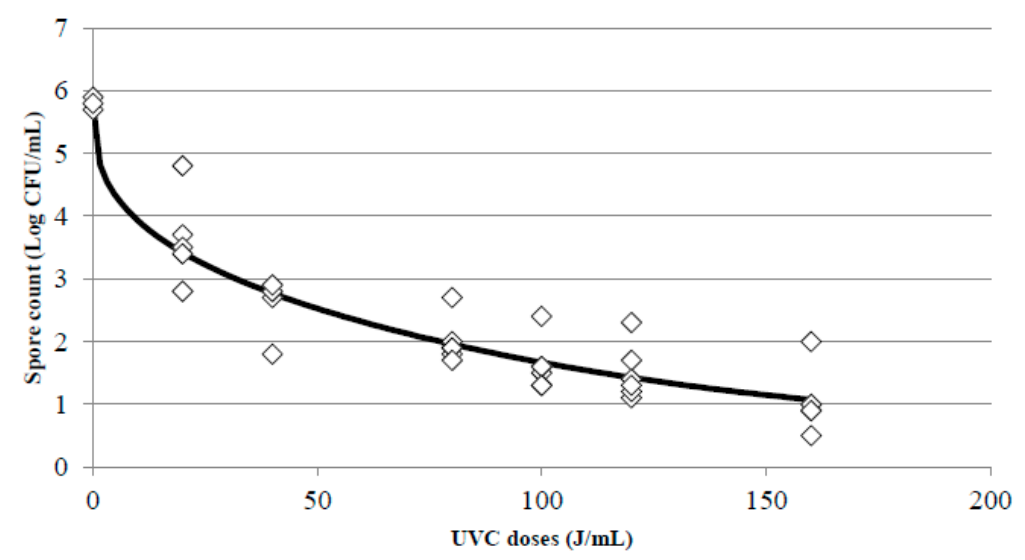

Figure 6. Surviving spores of B. subtilis inoculated in whole milk after T2 (A) and T3 (B) treatments at different UVC doses and adjustment of the data to the Weibull with tail inactivation model using the tool GInaFIT. $(\diamond)$ indicates the experimental data and the black line the estimated curve once adjusted to the model.

Table 4 also shows the $4 \mathrm{D}$ value calculated by the GInaFit software in the treatments and models were it was possible. In $\mathrm{T} 1$ treatments, the accuracy of the adjustment was not good for any inactivation model and $4 \mathrm{D}$ values were not provided. $4 \mathrm{D}$ values in $\mathrm{T} 2$ and $\mathrm{T} 3$ treatments were provided by the Weibull with tail and Biphasic Log-Linear models. In T3 treatments with skim milk the 4D value was also estimated adjusting to the Log-Linear with tail model. Nevertheless, the best adjustment was for the Weibull and Biphasic models. 
A

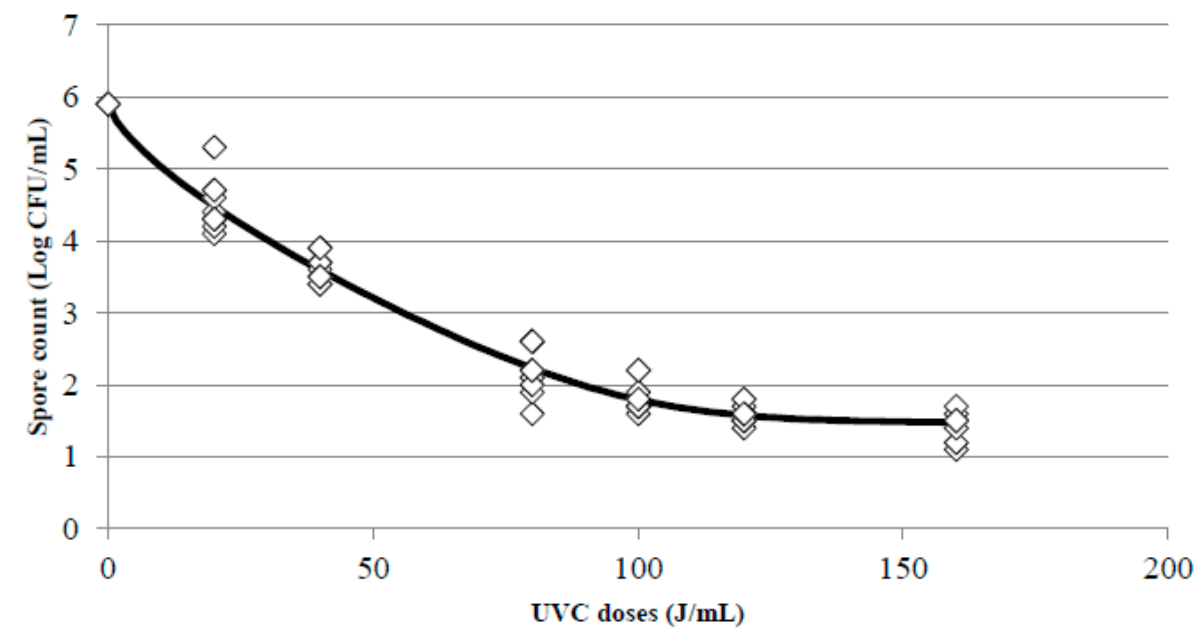

B

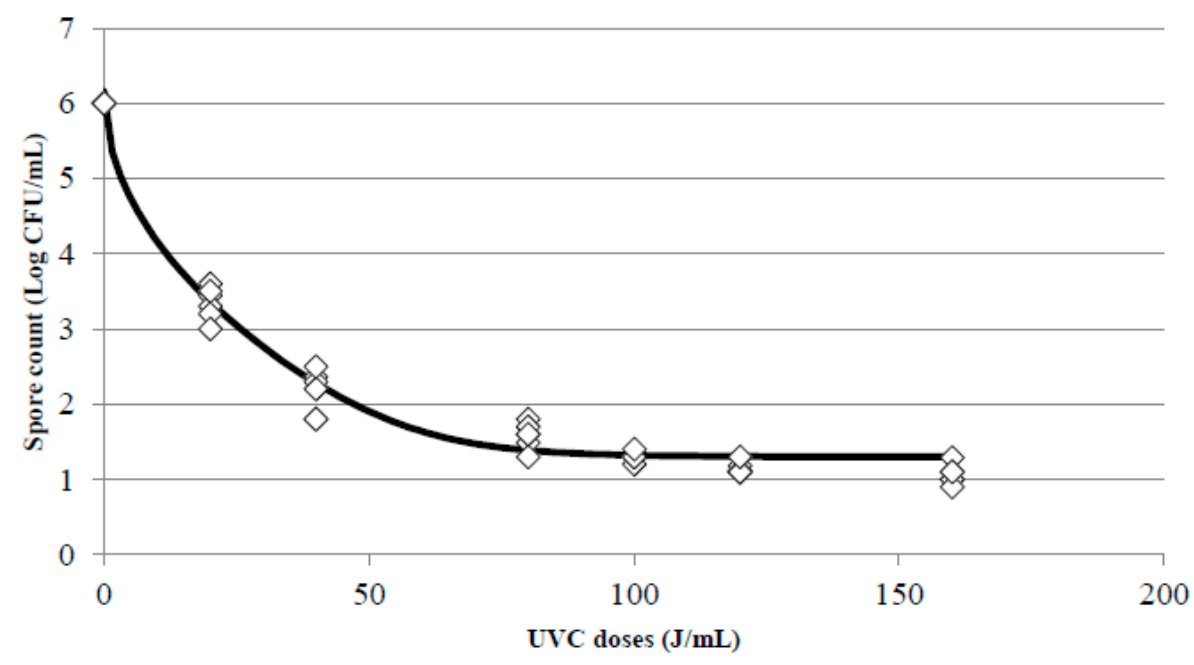

Figure 7. Surviving spores of B. subtilis inoculated in skim milk after T2 (A) and T3 (B) treatments at different UVC doses and adjustment of the data to the Weibull with tail inactivation model using the tool GInaFIT. $(\diamond)$ indicates the experimental data and the black line the estimated curve once adjusted to the model.

\section{Discussion}

In matrices with low absorption coefficient different studies were conducted with B. subtilis spores, a microorganism commonly used as a control organism in bioassays performed in water treated with UVC due to its moderate resistance and great consistency to UVC inactivation. Chang et al. [39] required approximately $36 \mathrm{~mJ} / \mathrm{cm}^{2}$ to reduce one log the initial load of B. subtilis in water while Sommer et al. [40] achieved this goal with a dose of $20-22 \mathrm{~mJ} / \mathrm{cm}^{2}$ in a liquid food model with an $\alpha(254)$ of $0.42 \mathrm{~cm}^{-1}$. Zhang et al. [41] obtained an inactivation of $0.81 \log$ when treated water with a dose of $78 \mathrm{~J} / \mathrm{mL}$. Reverter-Carrión et al. [33] obtained a reduction of $5 \log \mathrm{CFU} / \mathrm{mL}$ of spores of B. subtilis in PBS adjusted to an $\alpha(254)$ of $26 \mathrm{~cm}^{-1}$ with caramel after applying a dose of $7.5 \mathrm{~J} / \mathrm{mL}$ using the same reactor and the same strain of $B$. subtilis that the present study, where the maximum lethality achieved with a single pass was slightly higher than $1 \log \mathrm{CFU} / \mathrm{mL}$ after a dose of $160 \mathrm{~J} / \mathrm{mL}$, due to the greater $\alpha(254)$ of milk.

In whole and skim raw cow's milk, Choudhary et al. [18] studied the efficiency of UVC treatments on Bacillus cereus applying a dose of $11.187 \mathrm{~mJ} / \mathrm{cm}^{2}$ in a reactor with an inner diameter of $1.6 \mathrm{~mm}$ and a 
flow with a Re number of 713, obtaining a reduction of $2.65 \log C F U / \mathrm{mL}$ in whole milk and $1.78 \log$ in skim milk. These lethalities were similar to those obtained in the present study with a T3 treatment at a dose of $40 \mathrm{~J} / \mathrm{mL}\left(4165.6 \mathrm{~mJ} / \mathrm{cm}^{2}\right)$ and $20 \mathrm{~J} / \mathrm{mL}\left(2082.8 \mathrm{~mJ} / \mathrm{cm}^{2}\right)$ in whole and skim milk, respectively. As in the study of Choudhary et al. [18], in the present survey the efficiency of UVC treatments was higher in skim milk than in whole milk at small doses $(20 \mathrm{~J} / \mathrm{mL}$ and $40 \mathrm{~J} / \mathrm{mL})$, probably due to the $\alpha(254)$ of both types of milk and its turbidity value. However, these $\alpha(254)\left(220 \mathrm{~cm}^{-1}\right.$ and $170 \mathrm{~cm}^{-1}$ for whole and skim milk, respectively) were lower than the observed ones in the milk samples used in this study ( $801 \mathrm{~cm}^{-1}$ and $264 \mathrm{~cm}^{-1}$ for whole and skim milk, respectively). This difference may be because, in this study, commercial milk was used, which in addition to the UHT treatment had suffered a homogenization treatment. The greater effectiveness observed in skim milk is also explained because of the estimated distance at which $B$. subtilis spores receive the most effective UVC radiation is higher than in whole milk, as can be seen in Table 2, and then when NET increases so do the probability of the presence of the spores within this zone.

Regarding the effect of the application of UVC treatments in other matrices of high $\alpha(254)$, Bandla et al. [42] evaluated the effect of a dose of $11,187 \mathrm{~mJ} / \mathrm{cm}^{2}$ on Bacillus cereus spores in a soybean drink with an $\alpha(254)$ of $163 \mathrm{~cm}^{-1}$, lower than that reported in the milks used in this study. The reactor used was a spiral tube with two different internal diameters $(1.6 \mathrm{~mm}$ and $3.2 \mathrm{~mm})$, generating two values of Re number that were higher than those achieved in this study (Table 1). Due to that, they reported reductions of 3.22 and $1.66 \log \mathrm{CFU} / \mathrm{mL}$ with the smallest and largest diameter, respectively. In this study, reductions of $1.47 \mathrm{log}$ were reported for a dose of $20 \mathrm{~J} / \mathrm{mL}$ equivalent to $2,082.8 \mathrm{~mJ} / \mathrm{cm}^{2}$ in the T3 treatment and $4 \log \mathrm{CFU} / \mathrm{mL}$ for a dose of $80 \mathrm{~J} / \mathrm{mL}$ (equivalent to $8,323 \mathrm{~mJ} / \mathrm{cm}^{2}$ ).

These results indicate that in matrices with a high absorption coefficient, the Re number effect influences the lethality achieved. This result can be explained by the "boundary layer theory" proposed by Prandtl (1925) [43], whereby a moving fluid tends to lose speed when it is in contact with a small adjacent layer of solid due to friction losses. This phenomenon is what would happen in the reactor when the flowing matrix is in contact with the quartz that protects the lamp, losing speed and thus decreasing the Re number, including the possibility of creating different layers that would not change its depth when passes throughout the reactor. This causes that in matrices of high $\alpha(254)$, the layer closest to the source of emission of UVC radiation is overexposed, but the inner layers do not receive a sufficient lethal dose. In this type of matrix, to increase the number of passes through the reactor (NET) increases, therefore, the probability that a particular particle is in the area of highest exposure to UVC radiation, increasing the lethal effect. Therefore, in matrices of high absorption coefficient, it seems more effective to increase the number of passes or NET value than to increase the Re value in order to obtain greater reductions.

The high resistance of bacterial spores to UHPH treatments has already been described in milk by Amador-Espejo et al. [32], observing that B. subtilis has a higher resistance to these treatments than the spores of other bacteria. In order to achieve significant reductions of at least $5 \log$ of this microorganism, it was necessary to increase the pressure to $300 \mathrm{MPa}$ and preheating the milk to a temperature of at least $80^{\circ} \mathrm{C}$ to increase the thermal effect. Thus, to combine UHPH with another technology or unfavourable condition seems interesting in order to increase lethality and achieve significant reductions of bacterial spores in foods. In this study it has been assessed whether the combination of UHPH with UVC could be an option to increase the effectiveness of both treatments, reducing the number of passes needed in the case of UVC, and the need to increase the temperature in the case of UHPH, which a priori would less affect the properties of the matrix. However, in this study, there was no clear synergistic or additive effect between both technologies. In fact, in some cases, lethalities obtained on B. subtilis spores after applying combined treatments, especially in skim milk, decreased concerning single UVC treatments at the same doses. These results could be explained by the modifications caused by UHPH on the structures of fat globules and casein micelles [44]. Table 5 shows the effect of UHPH on the absorption coefficient and the turbidity of milks used in this study, showing that UHPH treatments increase the turbidity and the $\alpha(254)$ values in both whole and skim milk. The changes suffered by the matrix 
may have high relevance in the effectiveness of the combination of technologies since in a previous study Reverter-Carrión et al. [33] observed an additive effect when both technologies were applied over the same microorganism but inoculated in a buffered solution (PBS) without the interference of suspended particles.

Table 5. Effect of ultra-high pressure homogenization (UHPH) treatments on the absorption coefficient and the turbidity of whole and skim milk.

\begin{tabular}{ccccc}
\hline \multirow{2}{*}{ Optical Parameter } & \multicolumn{2}{c}{ Skim Milk } & \multicolumn{2}{c}{ Whole Milk } \\
\cline { 2 - 5 } & Before UHPH & After UHPH & Before UHPH & After UHPH \\
\hline$\alpha(254)\left(\mathrm{cm}^{-1}\right)$ & $264 \pm 0.03$ & $412 \pm 0.02$ & $801 \pm 0.02$ & $1012 \pm 0.02$ \\
Turbidity (NTU) & $18,416 \pm 0.04$ & $21,630 \pm 0.03$ & $77,967 \pm 0.01$ & $102,458 \pm 0.01$ \\
\hline
\end{tabular}

Table 4 shows the estimated $4 \mathrm{D}_{\mathrm{uvc}}$ values for B. subtilis in whole and skim milk once the inactivation curve was fit to a Weibull with tail model. The most effective treatment in whole milk showed to be the $\mathrm{T} 3$, being necessary a dose of $91.2 \mathrm{~J} / \mathrm{mL}$ to inactivate $4 \log \mathrm{CFU} / \mathrm{mL}$ of spores, but the difference with the T2 treatments was small. On the contrary, T3 treatments showed to be much more efficient in skim milk, where a dose of $41.6 \mathrm{~J} / \mathrm{mL}$ would be enough to achieve this goal. No previous references were found of $\mathrm{D}_{\mathrm{uvc}}$ values for B. subtilis or any other sporulated bacteria in milk. Crook et al. [2] reported a $\mathrm{D}_{\mathrm{uvc}}$ value of $0.73 \mathrm{~J} / \mathrm{mL}$ for L. monocytogenes in milk, and of $0.556 \mathrm{~J} / \mathrm{mL}$ for E. coli, but these bacteria are much more sensitive to UVC than B. subtilis [9]. Concerning other matrices, Nicholson et al. [45] calculated the $\mathrm{D}_{\mathrm{uvc}}$ value for spores of $B$. subtilis in phosphate-buffered saline solution, estimating it in $120 \mathrm{~J} / \mathrm{m}^{2}$, what implies a dose of $480 \mathrm{~J} / \mathrm{m}^{2}$ to achieve a 4 D reduction. In the present survey, for the most effective treatment (T3), the estimated $4 \mathrm{D}_{\mathrm{uvc}}$ would be above $43,300 \mathrm{~J} / \mathrm{m}^{2}$. In that case, the least interfering matrix used there would justify the differences.

\section{Conclusions}

Recirculation seems to be a good strategy in the application of UVC treatments to matrices with a high degree of interference, such as milk, since the mixing effect ensures that microbial spores (or planktonic cells) will be in the area of maximum efficacy (where the action of UVC radiation is the highest) enough time to be inactivated. This hypothesis seems to be demonstrated by the fact that NET was the most determining variable in order to predict the lethality caused over the spores of B. subtilis. However, the possibility of weakening the resistance of the spores of B. subtilis by applying another physical treatment in advance, such as UHPH, proved to be ineffective in this case, despite the favorable references observed previously [33,46], probably due to the effect of UHPH on the matrix that increases the protective effect on spores. It seems that achieving the goal of a commercial sterilization of milk by means of UVC is complicated since the estimated $4 \mathrm{D}_{\mathrm{uvc}}$ values of the most effective treatments are too high.

Author Contributions: Conceived and designed the experiments: M.M.-G., J.N.S.-G., M.M.H.-H., R.G. and A.X.R.-S.; performed the experiments: M.M.-G., J.N.S-G. and I.C.-T.; analysed the data: M.M.-G., M.M.H.-H., R.G. and A.X.R.-S; wrote the paper: M.M.-G. and A.X.R.-S.

Funding: This research was funded by the Spanish Ministry of Economy and Competitiveness, project AGL2014-60005-R, co-funded by FEDER.

Acknowledgments: The authors acknowledge the financial support received from the research project AGL2014-60005-R of the Spanish Ministry of Education and Science.

Conflicts of Interest: The authors declare no conflict of interest. 


\section{References}

1. Gouma, M.; Gayán, E.; Raso, J.; Condón, S.; Álvarez, I. UV-Heat Treatments for the Control of Foodborne Microbial Pathogens in Chicken Broth. Biomed. Res. Int. 2015, 2015, 1-12. [CrossRef] [PubMed]

2. Crook, J.A.; Rossitto, P.V.; Parko, J.; Koutchma, T.; Cullor, J.S. Efficacy of ultraviolet (uv-c) light in a thin-film turbulent flow for the reduction of milkborne pathogens. Foodborne Pathog. Dis. 2015, 12, 506-513. [CrossRef] [PubMed]

3. Guerrero-Beltrán, J.A.; Barbosa-Cánovas, G.V. Advantages and Limitations on Processing Foods by UV Light. Food Sci. Technol. Int. 2004, 10, 137-147. [CrossRef]

4. Koutchma, T. Ultraviolet Light for Decontamination and Preservation of Beverages, Liquid Foods, and Ingredients. In Reference Module in Food Science; Elsevier: Amsterdam, The Netherlands, 2016.

5. Tran, M.T.T.; Farid, M. Ultraviolet treatment of orange juice. Innov. Food Sci. Emerg. Technol. 2004, 5, 495-502. [CrossRef]

6. Coohill, T.P.; Sagripanti, J.-L. Overview of the Inactivation by $254 \mathrm{~nm}$ Ultraviolet Radiation of Bacteria with Particular Relevance to Biodefense. Photochem. Photobiol. 2008, 84, 1084-1090.

7. Choudhary, R.; Bandla, S. Ultraviolet Pasteurization for Food Industry. Int. J. Food Sci. Nutr. Eng. 2012, 2, 12-15. [CrossRef]

8. Hijnen, W.A.M.; Beerendonk, E.F.; Medema, G.J. Inactivation credit of UV radiation for viruses, bacteria and protozoan (oo)cysts in water: A review. Water Res. 2006, 40, 3-22. [CrossRef]

9. Gayán, E.; Álvarez, I.; Condón, S. Inactivation of bacterial spores by UV-C light. Innov. Food Sci. Emerg. Technol. 2013, 19, 140-145. [CrossRef]

10. Cilliers, F.P.; Gouws, P.A.; Koutchma, T.; Engelbrecht, Y.; Adriaanse, C.; Swart, P. A microbiological, biochemical and sensory characterisation of bovine milk treated by heat and ultraviolet (UV) light for manufacturing Cheddar cheese. Innov. Food Sci. Emerg. Technol. 2014, 23, 94-106. [CrossRef]

11. Matak, K.E.; Churey, J.J.; Worobo, R.W.; Sumner, S.S.; Hovingh, E.; Hackney, C.R.; Pierson, M.D. Efficacy of UV light for the reduction of Listeria monocytogenes in goat's milk. J. Food Prot. 2005, 68, 2212-2216. [CrossRef]

12. Matak, K.E. Effects of UV Irradiation on the Reduction of Bacterial Pathogens and Chemical Indicators of Milk. Ph.D. Thesis, Virginia Polytechnic Institute and State University, Blacksburg, VA, USA, 2004.

13. Yin, F.; Zhu, Y.; Koutchma, T.; Gong, J. Inactivation and potential reactivation of pathogenic Escherichia coli O157: H7 in bovine milk exposed to three monochromatic ultraviolet UVC lights. Food Microbiol. 2015, 49, 74-81. [CrossRef] [PubMed]

14. Lu, G.; Li, C.; Liu, P. UV inactivation of milk-related microorganisms with a novel electrodeless lamp apparatus. Eur. Food Res. Technol. 2011, 233, 79-87. [CrossRef]

15. Donaghy, J.; Keyser, M.; Johnston, J.; Cilliers, F.P.; Gouws, P.A.; Rowe, M.T. Inactivation of Mycobacterium avium ssp. paratuberculosis in milk by UV treatment. Lett. Appl. Microbiol. 2009, 49, 217-221. [CrossRef] [PubMed]

16. Engin, B.; Karagul Yuceer, Y. Effects of ultraviolet light and ultrasound on microbial quality and aroma-active components of milk. J. Sci. Food Agric. 2012, 92, 1245-1252. [CrossRef]

17. Krishnamurthy, K.; Demirci, A.; Irudayaraj, J.M. Inactivation of Staphylococcus aureus in milk using flow-through pulsed UV-light treatment system. J. Food Sci. 2007, 72, M233-M239. [CrossRef]

18. Choudhary, R.; Bandla, S.; Watson, D.G.; Haddock, J.; Abughazaleh, A.; Bhattacharya, B. Performance of coiled tube ultraviolet reactors to inactivate Escherichia coli W1485 and Bacillus cereus endospores in raw cow milk and commercially processed skimmed cow milk. J. Food Eng. 2011, 107, 14-20. [CrossRef]

19. Pereira, R.V.; Bicalho, M.L.; Machado, V.S.; Lima, S.; Teixeira, A.G.; Warnick, L.D.; Bicalho, R.C. Evaluation of the effects of ultraviolet light on bacterial contaminants inoculated into whole milk and colostrum, and on colostrum immunoglobulin G. J. Dairy Sci. 2014, 97, 2866-2875. [CrossRef]

20. Reinemann, D.J.; Gouws, P.; Cilliers, T.; Houck, K.; Bishop, J.R. New Methods for UV Treatment of Milk for Improved Food Safety And Product Quality. In Proceedings of the American Society of Agricultural and Biological Engineers, Portland, OR, USA, 9-12 July 2006; p. 1.

21. Altic, L.C.; Rowe, M.T.; Grant, I.R. UV light inactivation of Mycobacterium avium subsp. paratuberculosis in milk as assessed by FASTPlaqueTB phage assay and culture. Appl. Environ. Microbiol. 2007, 73, 3728-3733. [CrossRef] 
22. Rossitto, P.V.; Cullor, J.S.; Crook, J.; Parko, J.; Sechi, P.; Cenci-Goga, B.T. Effects of uv irradiation in a continuous turbulent flow uv reactor on microbiological and sensory characteristics of cow's milk. J. Food Prot. 2012, 75, 2197-2207. [CrossRef]

23. Bintsis, T.; Litopoulou-Tzanetaki, E.; Robinson, R.K. Existing and potential applications of ultraviolet light in the food industry-A critical review. J. Sci. Food Agric. 2000, 80, 637-645. [CrossRef]

24. Koutchma, T.; Parisi, B.; Patazca, E. Validation of UV coiled tube reactor for fresh juices. J. Environ. Eng. Sci. 2007, 6, 319-328. [CrossRef]

25. Koutchma, T.; Forney, L.J.; Moraru, C.I. Ultraviolet Light in Food Technology: Principles and Applications; CRC Press: Boca Raton, FL, USA, 2009.

26. López-Malo, A.; Palou, E. Ultraviolet Light and Food Preservation. In Novel Food Processing Technologies; CRC Press: Boca Raton, FL, USA, 2004; pp. 405-421.

27. Gayán, E.; Monfort, S.; Álvarez, I.; Condón, S. UV-C inactivation of Escherichia coli at different temperatures. Innov. Food Sci. Emerg. Technol. 2011, 12, 531-541. [CrossRef]

28. Pereda, J.; Ferragut, V.; Quevedo, J.M.; Guamis, B.; Trujillo, A.J. Effects of ultra-high-pressure homogenization treatment on the lipolysis and lipid oxidation of milk during refrigerated storage. J. Agric. Food Chem. 2008, 56, 7125-7130. [CrossRef] [PubMed]

29. Picart, L.; Thiebaud, M.; René, M.; Guiraud, J.P.; Cheftel, J.C.; Dumay, E. Effects of high pressure homogenisation of raw bovine milk on alkaline phosphatase and microbial inactivation. A comparison with continuous short-time thermal treatments. J. Dairy Res. 2006, 73, 454-463. [CrossRef]

30. Hayes, M.G.; Fox, P.F.; Kelly, A.L. Potential applications of high pressure homogenisation in processing of liquid milk. J. Dairy Res. 2005, 72, 25-33. [CrossRef]

31. Poliseli-Scopel, F.H.; Hernández-Herrero, M.; Guamis, B.; Ferragut, V. Sterilization and aseptic packaging of soymilk treated by ultra high pressure homogenization. Innov. Food Sci. Emerg. Technol. 2014, 22, 81-88. [CrossRef]

32. Amador Espejo, G.G.; Hernández-Herrero, M.M.; Juan, B.; Trujillo, A.J. Inactivation of Bacillus spores inoculated in milk by Ultra High Pressure Homogenization. Food Microbiol. 2014, 44, 204-210. [CrossRef]

33. Reverter-Carrión, L.; Sauceda-Gálvez, J.N.; Codina-Torrella, I.; Hernández-Herrero, M.M.; Gervilla, R.; Roig-Sagués, A.X. Inactivation study of Bacillus subtilis, Geobacillus stearothermophilus, Alicyclobacillus acidoterrestris and Aspergillus niger spores under Ultra-High Pressure Homogenization, UV-C light and their combination. Innov. Food Sci. Emerg. Technol. 2018, 48, 258-264. [CrossRef]

34. Asociación Española de Normalización y Certificación. Quantitative Suspension Test for the Evaluation of Sporicidal Activity of Chemical Disinfectants Used in Food, Industrial, Domestic and Institutional Areas-Test Method and Requirements; AENOR: Madrid, Spain, 2002.

35. Rahn, R.O. Potassium Iodide as a Chemical Actinometer for $254 \mathrm{~nm}$ Radiation: Use of lodate as an Electron Scavenger. Photochem. Photobiol. 1997, 66, 450-455. [CrossRef]

36. Linden, K.G.; Mofidi, A.A. Disinfection Efficiency and Dose Measurement of Polychromatic Uv Light; IWA Publishing: London, UK, 2004.

37. Müller, A.; Günthner, K.A.; Stahl, M.R.; Greiner, R.; Franz, C.M.A.P.; Posten, C. Effect of physical properties of the liquid on the efficiency of a UV-C treatment in a coiled tube reactor. Innov. Food Sci. Emerg. Technol. 2015, 29, 240-246. [CrossRef]

38. Geeraerd, A.H.; Valdramidis, V.P.; Van Impe, J.F. GInaFiT, a freeware tool to assess non-log-linear microbial survivor curves. Int. J. Food Microbiol. 2005, 102, 95-105. [CrossRef] [PubMed]

39. Chang, J.C.H.; Ossoff, S.F.; Lobe, D.C.; Dorfman, M.H.; Dumais, C.M.; Qualls, R.G.; Johnson, J.D. UV inactivation of pathogenic and indicator microorganisms. Appl. Environ. Microbiol. 1985, 49, 1361-1365. [PubMed]

40. Sommer, R.; Cabaj, A.; Sandu, T.; Lhotsky, M. Measurement of UV radiation using suspensions of microorganisms. J. Photochem. Photobiol. B Biol. 1999, 53, 1-6. [CrossRef]

41. Zhang, Y.; Zhou, L.; Zhang, Y. Investigation of $\mathrm{UV}-\mathrm{TiO}_{2}$ photocatalysis and its mechanism in Bacillus subtilis spore inactivation. J. Environ. Sci. 2014, 26, 1943-1948. [CrossRef] [PubMed]

42. Bandla, S.; Choudhary, R.; Watson, D.G.; Haddock, J. UV-C treatment of soymilk in coiled tube UV reactors for inactivation of Escherichia coli W1485 and Bacillus cereus endospores. LWT-Food Sci. Technol. 2012, 46, 71-76. [CrossRef] 
43. Lagrée, P.-Y. Boundary layer separation and asymptotics from 1904 to 1969. Comptes Rendus Mécanique 2017, 345, 613-619. [CrossRef]

44. Pereda, J.; Ferragut, V.; Quevedo, J.M.; Guamis, B.; Trujillo, A.J. Effects of ultra-high pressure homogenization on microbial and physicochemical shelf life of milk. J. Dairy Sci. 2007, 90, 1081-1093. [CrossRef]

45. Nicholson, W.L.; Galeano, B. UV resistance of Bacillus anthracis spores revisited: Validation of Bacillus subtilis spores as UV surrogates for spores of B. anthracis Sterne. Appl. Environ. Microbiol. 2003, 69, 1327-1330. [CrossRef]

46. Sauceda-Gálvez, J.N.; Roca-Couso, R.; Martinez-Garcia, M.; Hernández-Herrero, M.M.; Gervilla, R.; Roig-Sagués, A.X. Inactivation of ascospores of Talaromyces macrosporus and Neosartorya spinosa by UV-C, $\mathrm{UHPH}$ and their combination in clarified apple juice. Food Control 2019, 98, 120-125. [CrossRef]

(C) 2019 by the authors. Licensee MDPI, Basel, Switzerland. This article is an open access article distributed under the terms and conditions of the Creative Commons Attribution (CC BY) license (http://creativecommons.org/licenses/by/4.0/). 